\title{
Septal myectomy after failed septal alcohol ablation
}

\author{
Eduard Quintana ${ }^{1}$, Pietro Bajona ${ }^{2,3}$, María José Arguis $^{4}$, Susanna Prat-González ${ }^{5}$ \\ ${ }^{1}$ Cardiovascular Surgery Department, Institut Clínic Cardiovascular, Hospital Clínic de Barcelona, University of Barcelona Medical School, \\ Barcelona, Spain; ${ }^{2}$ Department of Cardiovascular and Thoracic Surgery, University of Texas Southwestern Medical Center, Dallas, TX, USA; \\ ${ }^{3}$ Institute of Life Sciences, Sant'Anna School of Advanced Studies, Pisa, Italy; ${ }^{4}$ Anesthesiology Department, Hospital Clínic de Barcelona, University \\ of Barcelona Medical School, Barcelona, Spain; ${ }^{5}$ Department of Cardiology, Institut Clínic Cardiovascular, Hospital Clínic de Barcelona, University \\ of Barcelona Medical School, Barcelona, Spain \\ Correspondence to: Eduard Quintana. MD, PhD, FETCS. Cardiovascular Surgery Department, Institut Clínic Cardiovascular, Hospital Clínic de \\ Barcelona, University of Barcelona Medical School, Wing 10 - 3rd floor, Cardiovascular Surgery Intensive Care Unit, C/Villarroel 170 CP 08036 , \\ Barcelona, Spain. Email: equintan@clinic.cat.
}

\begin{abstract}
Despite septal myectomy remaining the gold standard septal reduction therapy for hypertrophic obstructive cardiomyopathy (HOCM), there has been a disproportionate use of alcohol septal ablation (ASA) worldwide. Absolute resolution of left ventricular outflow tract (LVOT) obstruction with ASA is not achieved in a substantial proportion of patients. The mechanisms of failure from ASA are partially understood and described. Residual obstruction in hypertrophic cardiomyopathy is associated with worse clinical outcomes and mortality. There is a growing number of patients who present with significant residual gradients after ASA and require a rescue septal myectomy operation, which then carries an increased risk of perioperative complications and life-long sequelae. This contrasts with the excellent outcomes achieved by septal myectomy without previous percutaneous intervention. Despite complete resolution of obstruction in rescue myectomy, the outcomes remain compromised by the prior ASA.
\end{abstract}

Keywords: Hypertrophic obstructive cardiomyopathy (HOCM); septal myectomy; reoperation; alcohol septal ablation (ASA)

Submitted Feb 26, 2017. Accepted for publication Mar 13, 2017.

doi: 10.21037/acs.2017.05.11

View this article at: http://dx.doi.org/10.21037/acs.2017.05.11

\section{Introduction}

Septal myectomy is considered the gold standard septal reduction therapy for patients with left ventricular outflow tract (LVOT) obstruction refractory to medical treatment (1). This procedure has been performed for about 50 years and continues to provide long-lasting and dramatic symptomatic improvement (2-4). For a heart surgeon practicing across the spectrum of surgical heart diseases, isolated septal myectomy may constitute the operation that offers the most rewarding change in quality of life and potentially restoring normal life span. The procedural mortality is currently described to be well below $1 \%$ and could be even safer than isolated mitral valve repair (5).

Worldwide, and particularly in Europe, alcohol septal ablation (ASA) has eclipsed surgery for hypertrophic obstructive cardiomyopathy (HOCM) in terms of procedures performed per year. In the 5 to 7 years preceding 2007, there had been more ASA procedures (estimated $>5,000)$ performed than myectomies in over 45 years (2). However, this incremental switch in practice has not been accompanied by the expected solid and long-term follow-up literature that one would expect in a procedure that started in 1995 (6). It is important to acknowledge that ASA has been adopted regardless of the evidence that early outcomes are inferior to those of septal myectomy in an equally experienced operator's hands. In fact, it has been described that periprocedural mortality and morbidity are higher with ASA (2,4,7-9).

Only scant data on long term survival following ASA is available. According to the two most important multicenter ASA reported registries, the average median survival follow 
up for the European registry is 5.7 years (10) and the mean follow up for the North American registry is 2.1 years (11). Nevertheless, the surge in unsuccessful ASA continues to increase, leading to the need for rescue septal myectomy. The outcomes of septal myectomy following a failed ASA remain underreported. It is the intention of this perspective article to provide additional insight into a poorly recognized clinical situation that HOCM surgeons face with increasing frequency.

\section{Residual gradients and need for reoperation after ASA}

Obstruction in hypertrophic cardiomyopathy (HCM) is inherently associated with heart failure symptoms, risk of arrhythmia and early death $(12,13)$. Even after a substantial LVOT obstruction relief, residual gradients affect longterm survival $(14,15)$.

During surgery, by virtue of direct inspection of septal anatomy, the operating surgeon can customize the resection purely according to individual differences. It is well known that septal myectomy provides resolution of LVOT obstruction virtually in all patients and provides superior outcomes in terms of LVOT obstruction resolution, than ASA (9,16-19).

Unfortunately, significant residual gradients are frequent after ASA. Historically, hemodynamic success after ASA is reported to be $70 \%$, with an approximate $20 \%$ incidence of recurrence of severe symptoms (20). In the most recent registries $(10,11)$, the percentage of patients who are lost at gradient/symptomatic follow-up or suffering obstruction requiring repeated SRT is $15-18 \%$. Such numbers should be taken in serious considerations especially in view of the aforementioned limited follow-up in ASA and with the low rates of reoperation after septal myectomy that nowadays are well below $2 \%(21)$.

\section{Mechanisms of failed ASA: anatomic and pathologic factors}

The mechanism in which ASA relies on to address LVOT obstruction is a targeted iatrogenic myocardial infarction at the septal level, by means of ethanol injection into one or more septal branches. With the use of preoperative imaging and intraprocedural echo contrast guidance, results may have improved over time. It is important to acknowledge that scarce information is available to understand the true pathological mechanisms of ethanol-induced myocardial injury in humans after ASA.

Different mechanisms of failure of ASA procedures could be summarized as follows:

\section{Inadequate preoperative patient selection}

Despite improved understanding of this disease by the medical community, poor indications leading to failure are still made. There are several anatomic features that can predict failure or poor outcome with ASA. Abnormal papillary muscle or secondary chordae attachment to the anterior mitral valve leaflet or subvalvular apparatus will continue to favor LVOT obstruction. This should constitute an additional reason for not pursuing ASA. In a significant proportion of patients, these anatomic features can be recognized beforehand with the use of magnetic resonance studies, 4D CT scan or occasionally by echocardiography.

Anomalous chordae attachments between the septum and the mitral valve apparatus can also contribute to obstruction and are not easily recognized preoperatively. This can constitute another mechanism of ASA failure that is not well acknowledged.

In patients with basal (LVOT) obstruction, the structures anatomically and physiologically leading to obstruction are the anterior septum, anterior free wall and the mitral valve. These areas are well targeted by a surgical approach. In contrast, ASA tends to impact on a more inferior region of the ventricular septum and usually extends into the right ventricular side of the septum at the midventricular level. Importantly, in up to $25 \%$ of patients undergoing ASA, the basal septum is spared (22). This again points into a frequent limitation of ASA.

Massive septal hypertrophy patients are another subgroup with poor expected ASA outcomes. Unfortunately, the likelihood of addressing different septal regions percutaneously is small, given the reasons provided here. Such cases can be challenging even for a surgical approach in very experienced hands and they depict a more complex phenotype. In certain instances, it can be necessary to offer a combined surgical transaortic and transapical approach, with excellent long-term outcomes (23).

\section{Unpredictable effects of ethanol at the septal level}

The ASA technique continues to be performed widely despite a poor understanding of its effects in the human heart. It appears that the mechanism by which the myocardium 
becomes altered differs from that of an atherosclerotic coronary occlusion myocardial infarction (24).

When suitable septal perforator arteries are present and ethanol is deployed to the selected septal myocardium, different histological changes may occur. One would expect the affected septum would ultimately "melt" or decrease in width, providing a consistent resolution of obstruction. While the septal reduction does occur in some patients, for many others it does not. An explanation for the persistent obstruction has to be provided by means of pathologic and histologic analysis.

Ethanol fixes the tissue in natural structures and stimulates polymorphonuclear leukocytes that are recruited into the affected area. At the coronary vessel level, the lumen becomes filled with thrombotic material and engorged with leukocytes but there is no extravasation. However, these cells cannot reach the fixed areas to start a cell-lytic process and the same occurs at the borders, where leukocytes concentrate but do not permeate. In fact, a few days after ASA, myofibrils and $\mathrm{Z}$ lines are still present in histologic specimens. Interestingly though, the necrotic area later stabilizes and shadowy myofibrils or "ghost cells" remain as fibrotic tissue, accounting for the remaining septal tissue (25). Thus, enzymatic degradation of septal tissue is prevented and can explain the considerable rate of ASA failure.

A possible explanation on why ethanol sometimes works is that some leukocytes reach the associated myocardium by collateral capillary networks and this allows an extent of enzymatic destruction of the injured myocardium. While speculative, this possibly explains the septal tissue "melting" associated with successful ASA.

\section{Coronary anatomy}

ASA is strongly limited by the coronary anatomy, which can vary significantly between individuals. In many instances, there may not be an available septal perforator artery that provides selective blood flow to the specific targeted area alone. The use of echocardiographic contrast allows for assessment and confirmation that the cannulated septal artery supplies the targeted septal region. Absence of a reliable available perforator artery should preclude ASA.

Ethanol injection is carried out with proximal balloon occlusion of the septal perforator artery to prevent injury to other myocardial areas (26). Usually these septal arteries arise from the left anterior descending (LAD) system, with the first or the second perforator being the most targeted vessels. In a recent study, $15 \%$ of patients undergoing
ASA had a non-LAD septal perforator target artery for the ASA. Failing to identify this characteristic can account for a proportion of failed ASA procedures; and in fact, half of those patients will have had a previously failed ASA procedure (27).

The different specifics of ethanol deployment such as volume infused, timing of balloon septal occlusion, flushing of saline (and volumes used) or simply direct reperfusion without flushing may vary according to the operator. All these factors may play a role in potential technical failures, however, this is still a matter of debate.

\section{Collateralization (coronary vascular network/collateral recruitment from septal branches)}

In the absence of coronary occlusions or obstructions, the traditionally held view is that the coronary arteries are functional end-arterial systems. With this physiology in mind, any occlusion to blood flow would lead to necrosis of the supplied area. This has already been proven not true for all cases. In fact, there can be adjacent or distal myocardial areas with overlapping circulation in a considerable proportion of normal hearts (28-31). Collateral arteries or arterioles extending beyond the vascular territorial borders (even to other main epicardial vessels) can exist. Interestingly, there has been collateral flow to a briefly occluded coronary artery sufficient to avoid electrocardiographic changes in $20-25 \%$ of individuals with normal coronary arteries (32). It is important not to forget this proven concept.

Recruitment of collaterals and extravasation of ethanol may carry extreme risk at the time of ASA. While this has been described [mainly in clinical case reports (33-38)], the risk is poorly detailed or even absent in current guidelines $(1,39)$. While ethanol flow to untargeted regions is a potential mechanism of failure of ASA, it can more importantly have devastating effects on untargeted myocardium.

\section{Inability to address endocardial fibrotic scar tissue}

Ethanol reaching the targeted muscle can eventually cause necrosis and melting of septal tissue, reducing LVOT obstruction. However, in no case will alcohol change the volume of fibrotic tissue. In most of the true HOCM cases, a dense contact lesion at the endocardial level (mitral-septal contact lesion) has developed over time. Another potential mechanism of failure of ASA is the inability to eradicate 


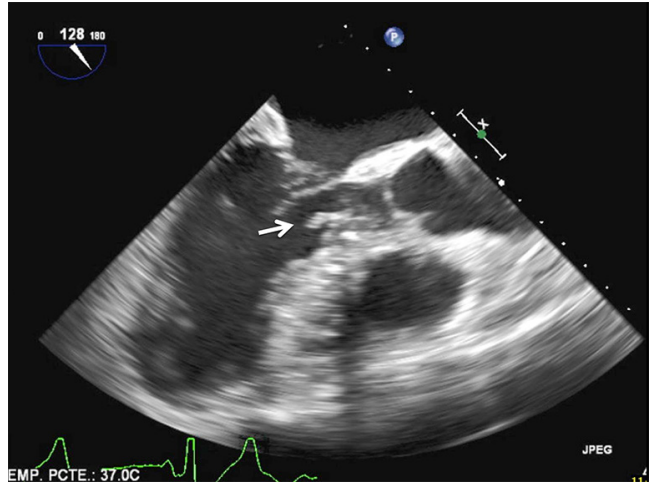

Figure 1 Transesophageal long axis view of the LVOT where a shelf in a subaortic position is visualized (arrow). Septal myectomy after failed alcohol septal ablation was performed in this patient. LVOT, left ventricular outflow tract.

a fixed subaortic scar that remains well adhered to the myocardium. In these cases, ASA may create a shelf at the LVOT significant enough to account for residual fixed or dynamic obstruction (Figure 1).

\section{Arrhythmia following ASA}

Particular lesions correspond to divergent post procedural characteristics among ASA and septal myectomy procedures. While ASA typically produces a right bundle branch block (in $36 \%$ of the patients), septal myectomy leaves a left bundle branch block (in approximately $40 \%$ of patients) (40). In terms of atrioventricular (AV) conductance, the risk of complete AV block following ASA is 10-20\% and for isolated septal myectomy, around 2\% (9).

There is still conflicting evidence regarding ventricular arrhythmia risk following ASA. A perceived increased risk secondary to the fibrotic scar left behind after ASA may justify the extensive use of cardioverter-defibrillators (ICDs) following this approach (41). There have been numerous reports pointing to potential increased risk of sudden death or need for ICD discharges following ASA (42-45). Conversely, myectomy does not add any extra risk (1). In fact, myectomy appears to protect from ventricular arrhythmia or post procedural ICD discharges in HOCM (46).

It is worth pointing out a very high incidence of inappropriate ICD discharges (affecting $25 \%$ of patients in $\geq 1$ occasions) and the worrying incidence of other complications (including endocarditis, lead dislodgment, tricuspid valve regurgitation and the need for reoperations) (47). Little is
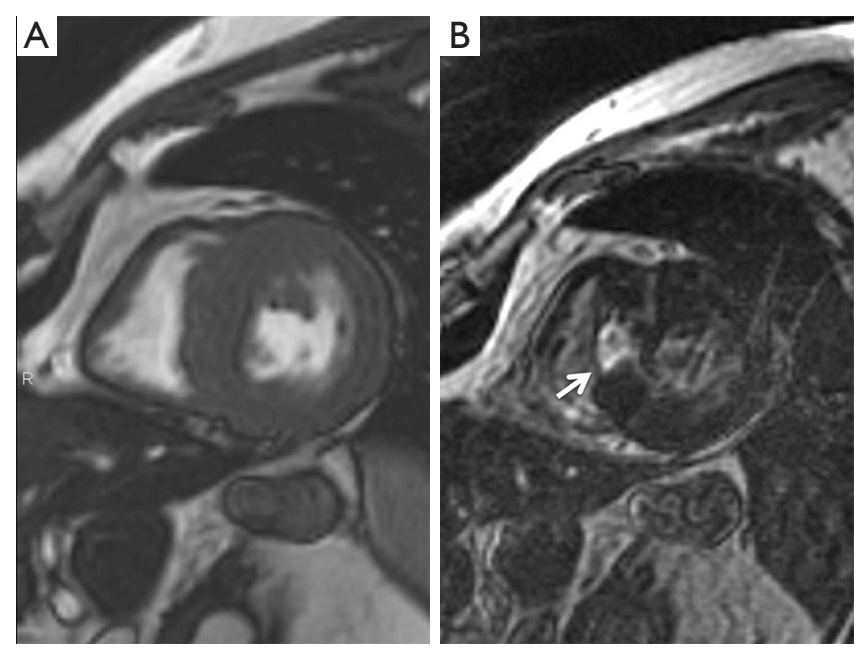

Figure 2 Cardiac magnetic resonance. (A) Cine image in short axis view. Severe midventricular septal hypertrophy is seen; (B) at the same level, late enhancement imaging showing focal area in the right side of midventricular septum, with bright (almost transmural) enhancement secondary to induced infarction from the alcohol septal ablation (arrow).

said about the long-term disturbance in the quality of life associated with this preventive strategy in HCM.

\section{Septal myectomy after failed ASA}

A thorough preoperative evaluation is required including 24 hours Holter electrocardiogram to rule out intermittent AV conduction abnormalities, ventricular tachycardia or atrial fibrillation (if patients do not have an ICD before the operation). Routine echocardiographic evaluation and magnetic resonance (or 4D CT scan in case of MRI incompatible ICD) study appear to be mandatory to assess the degree of scar tissue left behind (Figure 2) and judge the extent of resection required. Even if the ASA procedure was performed recently (e.g., months ago), the need for a repeat coronary angiogram should be considered, as iatrogenic lesions at the left main or the LAD system may have occurred. This is particularly true if patients suffer from angina.

Incidence of complete AV block after myectomy following failed ASA has been reported as high as 20\% (41). Special attention needs to be paid to the presence of iatrogenic right bundle branch block before surgery, as $\mathrm{RBBB}$ presence marks an increased risk of new complete AV block after myectomy (beyond 30\%), (Figure 3). 


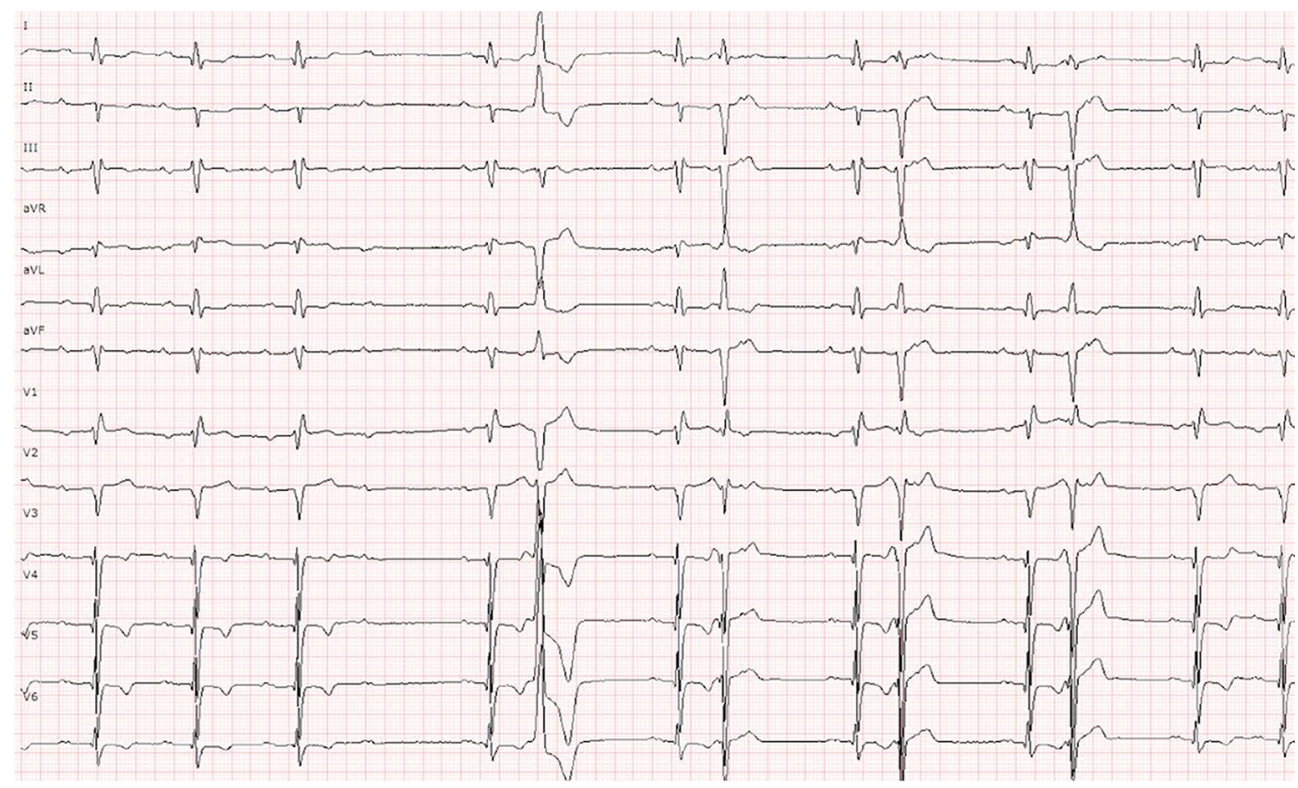

Figure 3 Preoperative surface electrocardiogram in a patient after failed septal alcohol ablation and prior to myectomy. Represents the same patient as in Figure 2. Second degree auriculoventricular (AV) block and right bundle branch block are both present. This patient developed complete AV block after successful myectomy.

\section{Surgery}

The general approach does not vary from regular isolated septal myectomy: full median sternotomy, ascending aorta/ right atrium cannulation, normothermic cardiopulmonary bypass and antegrade only cold blood cardioplegia are used. In the event other procedures are concomitantly required, the perfusate temperature and myocardial protection may vary accordingly.

In brief, after a low aortotomy extending into the noncoronary sinus, the aortic valve leaflets are separated with the same pump sucker and a malleable flat blade retractor. A left ventricular vent is not usually necessary. Identification of scar tissue helps in understanding the dynamic physiology (contact lesion) and guiding the resection. Scalpel resection is usually started at the nadir of the right cusp, $3-4 \mathrm{~mm}$ below the aortic valve and extending leftwards to the left trigone. The mitral valve is freed from scar attachments close to the left trigone. All anomalous chordae between the septum and mitral valve leaflet or anterior papillary muscle are divided. The depth of resection varies according to individual characteristics but is usually less than $1 \mathrm{~cm}$. After the first line of resection, better exposure of the caudal portion of the septum can be achieved by pressing with a sponge on the epicardium at the level of the right ventricle free wall. The use of skin hooks allows mobilization of distal muscle towards the LVOT and facilitates resection. An extended septal myectomy is performed as described before (48).

In patients suffering complete AV block after ASA, resection can be more aggressive and extend rightwards as well. In this case, the operation is simplified, as a proximal wider resection allows for simpler midventricular muscle excision.

After the desired resection is made, it is important to be able to appreciate the head of the papillary muscle through the LVOT. This typically helps to ensure that the basal subaortic septum and the midventricular areas will not cause residual obstruction. The left ventricle is then liberally irrigated with saline to remove any residual debris. Examination of aortic valve leaflets before aortotomy closure is warranted in order to identify inadvertent iatrogenic lesions to the aortic cusps. In patients with extensive diffuse septal hypertrophy or in a minority where exposure of distal LVOT segments is not feasible, a transapical approach may be judged as necessary (49). The operation then continues in a routine fashion: atrial and ventricular temporary epicardial pacing electrodes are placed and cardiopulmonary bypass abandoned.

It is routine practice and strongly suggested to invasively measure and document left ventricle to aorta gradients with direct needle puncture (50); this is done before and 
after cardiopulmonary bypass. Provocative maneuvers are performed to ensure no residual gradients are left behind. Occasionally after myectomy (at the discretion of the experienced team), isoprenaline challenge can be used to elucidate suspicious residual obstruction. This is not routinely done in our practice if a satisfactory myectomy has been performed, no provoked post-extrasystolic gradient is present and the septal morphology by echocardiography raises no concern.

The variability of macroscopic findings after ASA is high. In many patients, the septal tissue does not differ at all from myectomy without previous ASA. Occasionally only a small depression at the septal side is appreciated, in other instances, the septum shows no macroscopic alteration at all. Sometimes, a gritty texture is felt and at times, a fibrotic septum is encountered.

From a surgeon's perspective, septal myectomy following ASA is not more technically demanding. In fact, if there has been a true fibrotic reaction at the septum, increased tissue consistency facilitates tissue grasping and helps expose more distal ventricular areas. As a consequence of this, easier "en bloc" mobilization of muscle (by pulling it towards the aortic valve) facilitates a wide excision.

\section{Postoperative period and long-term follow up}

As indicated, in a substantial proportion of patients, complete AV block will occur regardless of an exquisite surgical technique. In this case, a dual chamber-pacing device should be placed very early after surgery as the likelihood of recovery beyond 4-5 days is low.

Beta-blocker therapy or baseline calcium channel blockers are reinstituted early postoperatively. Disopyramide should not be reinitiated. There is no need for anticoagulation in the absence of other reasons.

It has been observed that diastolic dysfunction occurs more frequently in myectomy after failed ASA. There has been a clear association of increased myocardial fibrosis (histologically) translating into worse diastolic function (measured by strain echocardiographic imaging). This is a consequence of scarring affecting $\mathrm{LV}$ areas beyond the previous obstructive regions and may account for residual heart failure symptoms. Perioperative mortality in myectomy after failed ASA was higher (6\%) than in matched patients undergoing septal myectomy as the first (and only) septal reduction therapy (0\%) (41).

Regardless of a successful septal myectomy with no residual obstruction, life-long follow-up is advised. Holter monitoring every 6-12 months is recommended to screen for atrial or ventricular arrhythmias and to continue to judge the need for ICD implantation.

\section{Conclusions}

Residual gradients and need for reoperation are both frequent after ASA. The mechanisms of ASA failure are varied and partially understood but are mostly ignored. A growing population requiring rescue septal myectomy after failed ASA is to be expected in the near future. A prior failed ASA compromises early outcomes of septal myectomy. Despite resolution of the obstruction, patients may experience life-long adverse and unexpected consequences from the initial attempt. Septal myectomy should remain the low-risk, first-line septal reduction therapy that offers excellent durable outcomes.

\section{Acknowledgements}

None.

\section{Footnote}

Conflicts of Interest: The authors have no conflicts of interest to declare.

\section{References}

1. American College of Cardiology Foundation/American Heart Association Task Force on Practice, American Association for Thoracic Surgery, American Society of Echocardiography; American Society of Nuclear Cardiology, et al. 2011 ACCF/AHA guideline for the diagnosis and treatment of hypertrophic cardiomyopathy: a report of the American College of Cardiology Foundation/ American Heart Association Task Force on Practice Guidelines. J Thorac Cardiovasc Surg 2011;142:e153-203.

2. Maron BJ. Controversies in cardiovascular medicine. Surgical myectomy remains the primary treatment option for severely symptomatic patients with obstructive hypertrophic cardiomyopathy. Circulation 2007;116:196206; discussion 206.

3. Ommen SR, Maron BJ, Olivotto I, et al. Long-term effects of surgical septal myectomy on survival in patients with obstructive hypertrophic cardiomyopathy. J Am Coll Cardiol 2005;46:470-6.

4. Maron BJ, Dearani JA, Ommen SR, et al. The case for 
surgery in obstructive hypertrophic cardiomyopathy. J Am Coll Cardiol 2004;44:2044-53.

5. Maron BJ, Dearani JA, Ommen SR, et al. Low operative mortality achieved with surgical septal myectomy: role of dedicated hypertrophic cardiomyopathy centers in the management of dynamic subaortic obstruction. J Am Coll Cardiol 2015;66:1307-8.

6. Sigwart U. Non-surgical myocardial reduction for hypertrophic obstructive cardiomyopathy. Lancet 1995;346:211-4.

7. Sorajja P, Valeti U, Nishimura RA, et al. Outcome of alcohol septal ablation for obstructive hypertrophic cardiomyopathy. Circulation 2008;118:131-9.

8. Yacoub MH. Surgical versus alcohol septal ablation for hypertrophic obstructive cardiomyopathy - The pendulum swings. Circulation 2005;112:450-2.

9. Maron BJ. Commentary and re-appraisal: surgical septal myectomy vs. alcohol ablation: after a decade of controversy and mismatch between clinical practice and guidelines. Prog Cardiovasc Dis 2012;54:523-8.

10. Veselka J, Jensen MK, Liebregts MA, et al. Longterm clinical outcome after alcohol septal ablation for obstructive hypertrophic cardiomyopathy: results from the Euro-ASA registry. Eur Heart J 2016;37:1517-23.

11. Nagueh SF, Groves BM, Schwartz LA, et al. Alcohol septal ablation for the treatment of hypertrophic obstructive cardiomyopathy a multicenter North American registry. J Am Coll Cardiol 2011;58:2322-8.

12. Maron MS, Olivotto I, Betocchi S, et al. Effect of left ventricular outflow tract obstruction on clinical outcome in hypertrophic cardiomyopathy. N Engl J Med 2003;348:295-303.

13. O'Mahony C, Jichi F, Pavlou M, et al. A novel clinical risk prediction model for sudden cardiac death in hypertrophic cardiomyopathy (HCM risk-SCD). Eur Heart J 2014;35:2010-20.

14. Sorajja P, Ommen SR, Holmes J, et al. Survival after alcohol septal ablation for obstructive hypertrophic cardiomyopathy. Circulation 2012;126:2374-80.

15. Veselka J, Tomašov P, Januška J, et al. Obstruction after alcohol septal ablation is associated with cardiovascular mortality events. Heart 2016. [Epub ahead of print].

16. Ralph-Edwards A, Woo A, McCrindle BW, et al. Hypertrophic obstructive cardiomyopathy: comparison of outcomes after myectomy or alcohol ablation adjusted by propensity score. J Thorac Cardiovasc Surg 2005;129:351-8.

17. Agarwal S, Tuzcu EM, Desai MY, et al. Updated Meta-
Analysis of septal alcohol ablation versus myectomy for hypertrophic cardiomyopathy. J Am Coll Cardiol 2010;55:823-34.

18. Firoozi S, Elliott PM, Sharma S, et al. Septal myotomymyectomy and transcoronary septal alcohol ablation in hypertrophic obstructive cardiomyopathy. A comparison of clinical, haemodynamic and exercise outcomes. Eur Heart J 2002;23:1617-24.

19. Qin JX, Shiota T, Lever HM, et al. Outcome of patients with hypertrophic obstructive cardiomyopathy after percutaneous transluminal septal myocardial ablation and septal myectomy surgery. J Am Coll Cardiol 2001;38:1994-2000.

20. Sorajja P, Binder J, Nishimura RA, et al. Predictors of an optimal clinical outcome with alcohol septal ablation for obstructive hypertrophic cardiomyopathy. Catheter Cardiovasc Interv 2013;81:E58-67.

21. Liebregts M, Vriesendorp PA, Mahmoodi BK, et al. A Systematic Review and Meta-Analysis of Long-Term Outcomes After Septal Reduction Therapy in Patients With Hypertrophic Cardiomyopathy. JACC Heart Fail 2015;3:896-905.

22. Valeti US, Nishimura RA, Holmes DR, et al. Comparison of surgical septal myectomy and alcohol septal ablation with cardiac magnetic resonance imaging in patients with hypertrophic obstructive cardiomyopathy. J Am Coll Cardiol 2007;49:350-7.

23. Agnew TM, Barratt-Boyes BG, Brandt PW, et al. Surgical resection in idiopathic hypertrophic subaortic stenosis with a combined approach through aorta and left ventricle. J Thorac Cardiovasc Surg 1977;74:307-16.

24. Baggish AL, Smith RN, Palacios I, et al. Pathological effects of alcohol septal ablation for hypertrophic obstructive cardiomyopathy. Heart 2006;92:1773-8.

25. Raute-Kreinsen U. Morphology of necrosis and repair after transcoronary ethanol ablation of septal hypertrophy. Pathol Res Pract 2003;199:121-7.

26. Angelini P. The "1st septal unit" in hypertrophic obstructive cardiomyopathy: a newly recognized anatomofunctional entity, identified during recent alcohol septal ablation experience. Tex Heart Inst J 2007;34:336-46.

27. Alkhouli M, Sajjad W, Lee J, et al. Prevalence of Non-Left Anterior Descending Septal Perforator Culprit in Patients With Hypertrophic Cardiomyopathy Undergoing Alcohol Septal Ablation. Am J Cardiol 2016;117:1655-60.

28. Seiler C, Stoller M, Pitt B, et al. The human coronary collateral circulation: development and clinical importance. Eur Heart J 2013;34:2674-82. 
29. Rentrop KP, Cohen M, Blanke H, et al. Changes in collateral Channel filling immediately after controlled coronary artery occlusion by an angioplasty balloon in human subjects. J Am Coll Cardiol 1985;5:587-92.

30. Helfant RH, Vokonas PS, Gorlin R. Functional importance of the human coronary collateral circulation. N Engl J Med 1971;284:1277-81.

31. Traupe T, Gloekler S, de Marchi SF, Werner GS, Seiler C. Assessment of the human coronary collateral circulation. Circulation 2010;122:1210-20.

32. Wustmann K, Zbinden S, Windecker S, et al. Is there functional collateral flow during vascular occlusion in angiographically normal coronary arteries? Circulation 2003;107:2213-20.

33. Rigopoulos A, Sepp R, Palinkas A, et al. Alcohol septal ablation for hypertrophic obstructive cardiomyopathy: collateral vessel communication between septal branches. Int J Cardiol 2006;113:e67-9.

34. Jimenez Valero S, Moreno R, Galeote GA. Alcohol septal ablation for obstructive hypertrophic cardiomyopathy: take care with the collaterals. Rev Esp Cardiol 2009;62:941-2.

35. Parham WA, Kern MJ. Apical infarct via septal collateralization complicating transluminal alcohol septal ablation for hypertrophic cardiomyopathy. Catheter Cardiovasc Interv 2003;60:208-11.

36. Agarwal SC, Purcell IF, Furniss SS. Apical myocardial injury caused by collateralisation of a septal artery during ethanol septal ablation. Heart 2005;91:e2.

37. Spacek M, Zemanek D, Tomasov P, et al. Early opening of dormant septal collaterals during alcohol septal ablation: a possible hazard of remote necrosis. Can J Cardiol 2013;29:1531.e5-7.

38. Chowdhary S, Galiwango P, Woo A, Schwartz L. Inferior infarction following alcohol septal ablation: a consequence of "collateral damage"? Catheter Cardiovasc Interv 2007;69:236-42.

39. Authors/Task Force members, Elliott PM, Anastasakis A, et al. 2014 ESC Guidelines on diagnosis and management of hypertrophic cardiomyopathy: the Task Force for the Diagnosis and Management of Hypertrophic Cardiomyopathy of the European Society of Cardiology (ESC). Eur Heart J 2014;35:2733-79.

40. Talreja DR, Nishimura RA, Edwards WD, et al. Alcohol septal ablation versus surgical septal myectomy: comparison of effects on atrioventricular conduction tissue. J Am Coll Cardiol 2004;44:2329-32.

41. Quintana E, Sabate-Rotes A, Maleszewski JJ, et al. Septal myectomy after failed alcohol ablation: Does previous percutaneous intervention compromise outcomes of myectomy? J Thorac Cardiovasc Surg 2015;150:159-67.e1.

42. Noseworthy PA, Rosenberg MA, Fifer MA, et al. Ventricular arrhythmia following alcohol septal ablation for obstructive hypertrophic cardiomyopathy. Am J Cardiol 2009;104:128-32.

43. ten Cate FJ, Soliman OI, Michels M, et al. Long-term outcome of alcohol septal ablation in patients with obstructive hypertrophic cardiomyopathy: a word of caution. Circ Heart Fail 2010;3:362-9.

44. Maron BJ, Spirito P, Shen WK, et al. Implantable cardioverter-defibrillators and prevention of sudden cardiac death in hypertrophic cardiomyopathy. JAMA 2007;298:405-12.

45. Vriesendorp PA, Liebregts M, Steggerda RC, et al. LongTerm outcomes after medical and invasive treatment in patients with hypertrophic cardiomyopathy. JACC Heart Fail 2014;2:630-6.

46. McLeod CJ, Ommen SR, Ackerman MJ, et al. Surgical septal myectomy decreases the risk for appropriate implantable cardioverter defibrillator discharge in obstructive hypertrophic cardiomyopathy. Eur Heart J 2007;28:2583-8.

47. Maron BJ, Shen WK, Link MS, et al. Efficacy of implantable cardioverter-defibrillators for the prevention of sudden death in patients with hypertrophic cardiomyopathy. N Engl J Med 2000;342:365-73.

48. Schaff HV, Said SM. Transaortic Extended Septal Myectomy for Hypertrophic Cardiomyopathy. Oper Tech Thorac Cardiovasc Surg 2012;17:238-50.

49. Kunkala MR, Schaff HV, Nishimura RA, et al. Transapical approach to myectomy for midventricular obstruction in hypertrophic cardiomyopathy. Ann Thorac Surg 2013;96:564-70.

50. Ashikhmina EA, Schaff HV, Ommen SR, et al. Intraoperative direct measurement of left ventricular outflow tract gradients to guide surgical myectomy for hypertrophic cardiomyopathy. J Thorac Cardiovasc Surg 2011;142:53-9.

Cite this article as: Quintana E, Bajona P, Arguis MJ, PratGonzález S. Septal myectomy after failed septal alcohol ablation. Ann Cardiothorac Surg 2017;6(4):394-401. doi: 10.21037/acs.2017.05.11 